\title{
COMMERCIAL BROADCASTING
}

\section{$B y$ BEVERLY F. FREDENDALL \\ National Broadcasting Company}

"One minute to go" and while the production man is trying to quiet those in the studio, the operator experiences once again that empty feeling in the pit of his stomach. Finally the cue is heard, signal lights flash, and the announcer swings into action. Once started, that "zero hour" feeling is safely past and the broadcast settles down to a perfect presentation of a well-rehearsed show.

Few people listening to programs while in an easy chair in their own homes have an opportunity to witness behind-thescenes activities in a broadcasting studio or to learn some of the technical aspects of network operation.

The term "radio network" has come to be increasingly familiar to all Americans. A network is composed of member stations in various parts of the country, which draw on programs originating by one of the major broadcasting companies. These programs fall into two classifications-sponsored and sustaining. Only $42 \%$ of the entire broadcast day is of the former type while the remainder is of the sustaining type. In the case of sponsored programs, member stations are paid to carry them, whereas the network principal originates and pays for the numerous sustaining programs. This latter type in- cludes an increasing number of Public Service features, such as "The NBC Symphony" and "The Army Hour," which contribute greatly to the public welfare.

This network service is as flexible as that which the newspapers receive from the great news agencies. Member stations have the privilege of using or rejecting available programs. In addition to network features it is highly desirable that they also provide listeners with "local" interest and news programs which are important in maintaining a station's popularity.

Most people believe that not only does the program reach the listener by radio but that the transmission of network programs from one broadcast station to another is also done entirely by radio. Such is not the case. The Federal Communications Commission has long ago ruled that wire lines shall be used between stations whenever they are available. This means that the same type wires that carry telephone conversations are used to carry local and transcontinental programs from station to station. Radio is resorted to mainly on special events broadcasts when wire line service is not available. The reason for this order is to conserve the crowded short-wave radio spectrum for (Continued on page 17)

\section{AUDIBLE SPECTRUM}



PHYSICAL OR SCIENTIFIC SCALE 
horizontal load on surfaces with a slope of $30^{\circ}$ or more, of five pounds per square foot of vertical projection; a live load on main cables of 200 pounds concentrated to take care of a man working.

Some of the other limitations of design are that a net supported directly on a cable should produce maximum cable sag of not more than six per cent of the span with an average sag of all cables of not more than three per cent. This will keep the end slopes of the cables flat enough so that they will not cast shadows. Sloping cables supporting nets should be limited to a maximum slope of about $20^{\circ}$ with the horizontal, except when facing the south.

Most of the buildings built in this area before 1933 do not have adequate strength to resist the pull of cables. If advantage is taken of earthquake bracing installed in buildings since 1933, they usually can be used to support and anchor the cables. However, special connections must be made in all cases, and in many cases some minor additional bracing is needed. When no building is available for anchorage, concrete "deadmen" weighing up to thirty tons are installed. When anchor cables are installed at steep angles, as they must be in some cases, the columns adjacent to "deadmen" carry extremely high loads and the design of footings may become quite serious.

\section{DESIGN PROCEDURE}

In designing the protective concealment for an industrial plant, the first step is to obtain complete photographs from the air of the area and enough information on the size, area, and roof construction of the building so that models of the entire area can be made.

After the models have been made, various camouflage schemes that blend in with the general camouflage plan in that area, as set up by the Office of Civilian Defense, are tried and photographs taken of the model. After one of these is chosen and developed to its final form, plans are made in order that this work can be carried on in the field.

\section{OFFICE OF CIVILIAN DEFENSE SET-UP FOR PROTECTIVE CONCEALMENT}

The Office of Civilian Defense has set up a standard procedure for the handling of all camouflage problems except those of the armed forces. Each city and county has appointed a camouflage officer whose duty is to act as Jiaison between the office of Civilian Defense, Protective Construction Division and industry in their respective areas. If any industrial firm desires information regarding the protective concealment of its plant, the Protective Concealment Division of the Office of Civilian Defense will make a complete study of it and report the results. The request is made through the local camoutlage officer who obtains the necssary information and transmits it to the O.C. D. They then proceed with a complete design of the camouflage as outlined above and obtain the army's approval of the final layout. The approved plan is then transmitted to the plant by the local camouflage officer. If the officials of the plant wish to carry out this plan, an O. C. D. approved camoufleur is employed to prepare detailed plans of construction and to handle the work in the conventional manner. If the industrial firm does not wish to do the work at this time, at some later date the army may require the work to be done if it feels it is essential that this particular plant be camouflaged.

\section{COMMERCIAL BROADCASTING}

(Continued from page 7)

services, usually international in scope. In one sense this is a handicap to the broadcaster for it is felt that there are times when other means of transmission would be superior to existing wire line facilities. For example, one school of thought believes that with the increasing knowledge and improvement in the use of the ultra high frequency radio spectrum (above thirty megacycles) an improvement in program transmission would result with no increase in cost of service, and without congestion in the radio spectrum.

The actual path over which network programs reach all member stations is a vast system of wire lines leased for twenty hours a day from the telephones companies at an annual aggregate rental of over three million dollars. Between New York and Chicago there is a "round robin" circuit and from Chicago to the Pacific Coast a "reversible" circuit. Added to this basic pattern are several supplementary "legs" radiating to all parts of the country and via short wave radio to other countries. A "round robin" circuit is one in which a program is always transmitted in a given direction around a "loop", regardless of the point of origin. For example when New York originates a program it travels over the telephone wires to Chicago via Schenectady and Cleveland, enters the Chicago network control board and passes out again to New York via Pittsburgh and Washington.

It is dead-ended at New York. Should a switch in program origin from New York to Chricago be recessary, Chicago would open the loop and New York would connect the incoming and outgoing circuits. The program thus travels eastward over a southern route and back again over a northern route. The elapsed time for program to travel to New York and back to Chicago again is one fifth of a second. Each station along the line gets a "feed" as if it were listening in on a party line. The

\section{Alumni Business and Professional Guide}

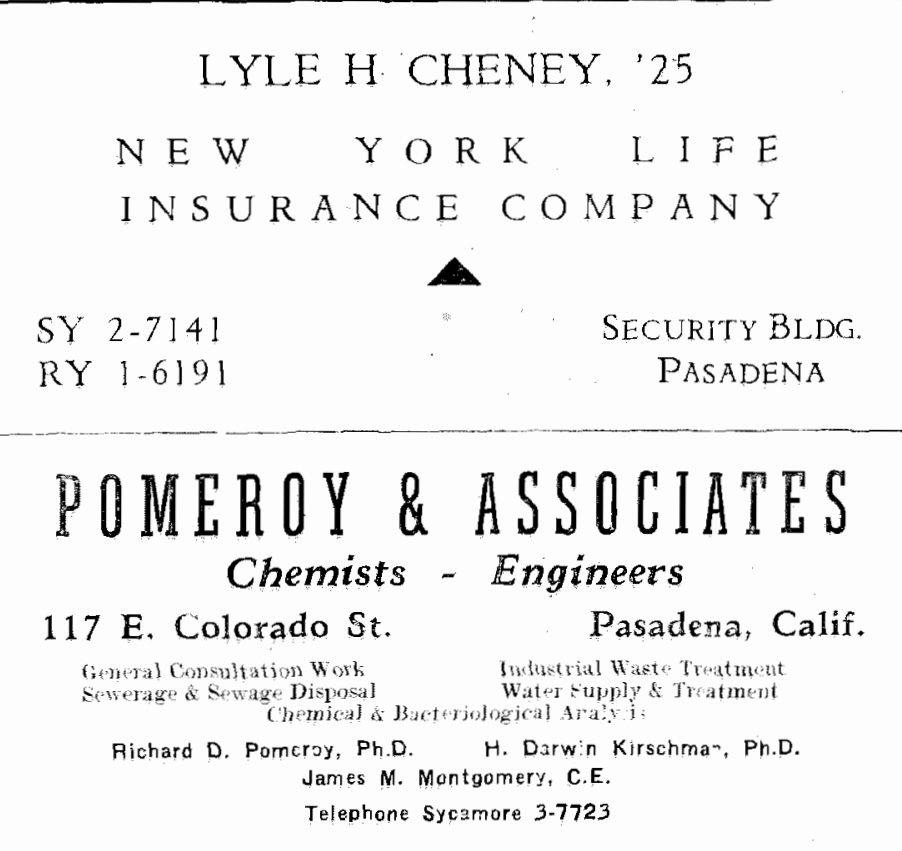


exact instant when each switching point must perform its duty must be accurately timed. This is accomplished by "cues." The normal between-program switching cue is the now famous chimes, a trademark of NBC programs, of three musical notes. Following the chimes cue, each station is allowed twenty seconds, in order to make an identification announcement and return to the network for resumption of the program.

If, however, during a program an announcer in New York wishes to introduce a speaker in Chicago he will usually end his introduction with words like "Mr. John Doe will speak to you from Chicago." "This constitutes a word cue, following which, both points must switch and continue program within one second. The National Farm and Home Hour is an example of this type of switching occurring between Washington and Chicago.

The circuit between Los Angeles and Chicago is "reversible." That is, the operators at the two ends of the circuit have control of the direction of program transmission. Their daily traffic schedules and cue sheets tell them exactly when to operate reversal keys associated with this line. Normally reversals take place between programs when the twenty second "local announce" period is available for switching. If, however, a fast switch is desired, as for example during a world news program when the New York announcer calls in his Australian associate, the Australian announcer delays his start six seconds, four of which are used in the actual reversal and two as a safety factor.

'The operator at the transmitting end of the line has control over the direction of transmission by the fact that he has applied a control voltage to the same pair of wires that carry the program. This operation simultaneously connects an amplifier and sends an impulse on to the next section of line. A reversal takes place as the result of operating a turn key at each end of the line. First, voltage is removed from one end of the line and all the relays progressively drop out. Next, a control voltage is applied from the other end of the line and a new set of relays reverses the anplifier connections and sends an impulse on to each successive section. A complete reversal takes four seconds.

Let's take a look now at some of the behind-the-scenes activities which precede a sponsored program. Officially all contact between the client and broadcaster is through the sales department, but as soon as a commercial program has been planned the broadcaster assigns a "production man" to the show whose duty it is to set in motion all necessary parts of the broadcasting organization. $\mathrm{He}$ is, in a sense the stage manager.

Once the program has been written, "auditions" are held for the selection of all who are required to take part. That is, the announcer, actors and others are given a tryout in order that the ones best suited to the various parts may be selected and engaged. This means that a studio with "live-microphones" must be used so the producer calls the studio assignment desk, for a studio and technical operator. The assignment desk consults

\section{Don't Forget the ALUMNI SEMINAR Sunday, April 11}

detailed charts covering all studios in the plant and, after picking an available one mutually agreeable to the production man, enter this new program rehearsal on the charts and upon the specific day's daily work schedule which in mimneographed form goes to all departments, and from which the engineering department schedules an operator.

Thus begins the first of a series of rehearsals totaling six to ten hours for a half hour show. First the rehearsals begin without the aid of a microphone or sound effects, with each part of the program rehearsing separately. That is, the acting and music is perfected separately until sound effects are added or when the time approaches for a dress rehearsal.

While the program is taking shape another department is busily engaged in lining up the proposed network. The traffic department, having received instructions from the sales department must now undertake the far reaching task of contacting each and every station the advertiser wants to engage for his program. Certain stations forming the basic network must usually be engaged as a unit while the supplementary groups and some individual stations may be added or omitted at the choice of the advertiser and in consideration of the availability of the stations.

An expensive-talent program must lave a sufficient number of station outlets together with their listening audience to insure not only the start of the program series, but its continuation. Consequently, a mutually beneficial agreement between member stations and the network principal was evolved, whereby, during certain hours of the day, each station would be available for network programs. The traffic department contracts each station whenever a new program series is to begin. One program, for instance, may necessitate as many as 500 telegrams before the network for that particular program is established.

The Press department now begins the job of publicizing the new show, and including its listing in regular published network schedules. It is an interesting fact that these schedules must be made out three weeks in advance.

Every piece of music used on network programs must be cleared through a central New York office to insure that at least four hours will elapse before the same selection is repeated. Talks and all written material must be checked by the Program department before they are approved for release. In short, the sale of any time period is governed by acceptability of the product, the program, the continuity for the specific period in question, and its relationship to preceding and following programs.

Frequently recordings are made of a dress rehearsal. This recording never goes on-the-air, but is made in order that those taking part may study their presentation to further improve the show. It is called a transcription, and is a record 16 inches in diameter which runs for fifteen minutes when played at the speed of $331 / 3$ revolutions per ninute instead of at the usual home phonograph speed of 78 R.P.M.

Let's depart from program building activities and again consider technical aspects of the art of broadcasting. While it is recognized that there are technical problems associated with all forms of transmission, only the primary ones concerned with wire line circuits will be mentioned since this is the system in current use. 
The human ear hears sound frequencies occupying a band 10 octaves wide, from 16 to approximately 17,000 cycles per second. A perfect system would pick up, transmit, and reproduce this entire band without distortion or impairment of any kind. In practice we know that each piece of equipment, from microphone to loud-speaker, in varying degrees contributes to a change in the original sound. A good studio plant will properly pick up and transmit electrically all 10 octaves and a good broadcast station can also function over the entire audio spectrum. The wire line from studio to local transmitter functions only $90 \%$ (i.e. 9 out of 10 octaves) from 16 to 8,000 cycles. Thus the highest quality from a broadcast transmitter takes place when that transmitter is being fed from its own local studios equal to $90 \%$ for a frequency band of 16 to 8,000 cycles. However, on a network program, where the transmitted frequency band is further limited both by technical and economic reasons to the narrower range from 80 to 5,000 cycles, the coverage is only $60 \%$.

The reduced upper limit primarily is governed by the 10 kilocycle separation of channels of the present broadcast band. Since two adjacent stations, separated by only 10,000 cycles must share the frequency band lying between them, it is clear that those frequencies above 5000 cycles emmitted by one station will jointly occupy a part of the band normally thought of as being associated with the other station. Under local receiving conditions this does little harm, but for distant reception when the desired station is received with weak signal intensity, the resultant crossing of programs is objectionable. Because of this fact the average present day receiver is manufactured for good selectivity by cutting off the upper frequency response limit at something less than 5000 cycles per second.

So far we have spoken only of the pick up and transmission of sound frequencies. The loudspeaker is the weakest single link in the entire chain. Loudspeakers vary from $93 \%$ coverage (40 to 17,000 cycles) thru $74 \%$ (60 to 10,000 cycles) usually found in a good broadcast plant, to the poor midget radio receiver of say $39 \%$ (200-3,000 cycles) coverage.

Additional factors affecting the quality of transmission of wire line circuits are harmonic distortion, noise, and phase shift. Harmonic distortion is caused by the generation of spurious overtones which result in "mushy" rather than clear and distinct sounds. Background noise means that the full intensity range found in a symphony orchestra cannot be transmitted correctly. Instead, the range must be compressed somewhat to fit technical limitations. Phase shift is evidenced by a peculiar chirping sound which tags along after the main part of the sound has already arrived. This phenomenon is known in radio vernacular as "birdies" and is caused by the various speeds of travel of the frequencies making up the original sound.

The losses encountered as sound frequencies flow along a telephone wire are far greater than those which the commercial power engineer deals with at 60 cycles over the high tension lines radiating from Boulder Dam.

Suppose all sound frequencies entering a telephone cable to be at equal intensity. As this energy flows along the line it decreases at an uneven rate. The loss for high frequencies is greater than low frequencies. At some distance from the start an equalizer is placed across the line in order to reduce the energy of the low frequencies to a point of equality with the highest frequency. With the aid of the equalizer the energy is again on a par, but so low that noise from other nearby wire circuits become troublesome. An amplifier is therefore inserted to again bring the energy up to the original level. This continual loss and rebuilding process is repeated each 40 miles for a cable circuit and about every 150 miles for an open wire circuit.

To illustrate the losses encountered in the use of wire lines for transcontinental service compare a 50 kilowatt short wave radio transmitter, operating between New York and Los Angeles, with the hypothetical condition where the same power might be used at the entrance to a transcontinental wire circuit. The radio link, although suffering to a considerable degree from selective fading and noise, would at least be understandable at the receiving end. Whereas, if it were possible to utilize $50 \mathrm{KW}$ at the imput to a bare telephone line, the small energy in watts delivered at the far end would be expressed by a decimal point followed by at least 35 zeros before the first significant figure, or, in terms of atomic physics, one electron every two seconds.

Now, you are invited to that easy chair near your radio. As you exercise your free choice with a careless turn of the wrist and bring your favorite program to life, may you enjoy it more for a wider knowledge of the processes which make such entertainment possible.

\section{STOP LEAKS and LOSSES OF VALUABLE LIQUIDS

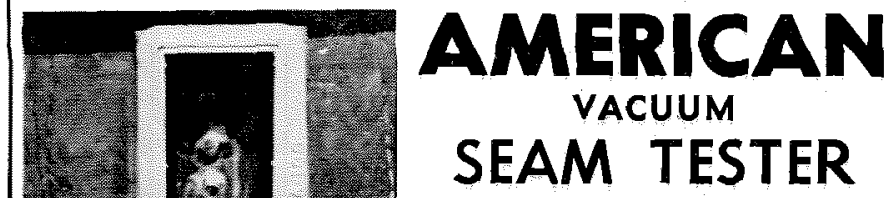 \\ Many storage tanks now in service have hidden, unsus- pected leaks which permit the loss of valuable liquids through seepage and evaporation. To- day the war needs of our country demand the utmost conservation of these valuable liquids. With the American Vacuum Seam Tester, new or old, square or round tanks with butt or lap welded or bolted seams, can be checked for leaks without being taken out of service. \\ Check your tanks now, com- plete information supplied up- on request.}

AMERICAN PIPE E STEEL CORPORATION Manufacturers and Distributors

ALHAMBRA,

CALIFORNIA 